FERREIRA, F.S., MOURA, M.S. e SILVEIRA, A.C.P. Implantação de Boas Práticas de Fabricação (BPF) em um laticínio de Piumhi-MG. PUBVET, Londrina, V. 5, N. 13, Ed. 160, Art. 1082, 2011.

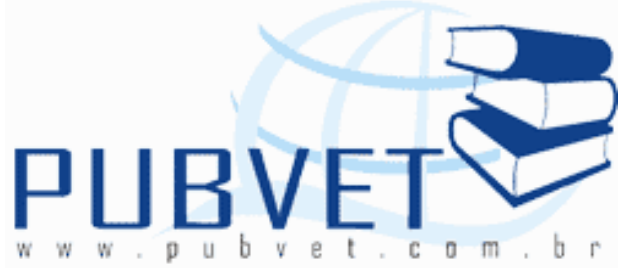

PUBVET, Publicações em Medicina Veterinária e Zootecnia.

\title{
Implantação de Boas Práticas de Fabricação (BPF) em um laticínio de Piumhi-MG
}

Fernanda Silva Ferreira ${ }^{1 *}$, Mariela Silva Moura ${ }^{2}$, Ana Carolina Portella Silveira $^{3}$

${ }^{1}$ Médica Veterinária

${ }^{2}$ Mestranda em Ciências Veterinárias pela Faculdade de Medicina Veterinária, Universidade Federal de Uberlândia. Uberlândia, MG.

${ }^{3}$ Doutoranda pelo Instituto de Genética e Bioquímica da Universidade Federal de Uberlândia. Uberlândia, MG.

*Autor para correspondência: Rua Ceará, s/n, Bloco 2D, CEP 38400-902, Uberlândia, MG, Brasil. E-mail: ferdinandasf@hotmail.com

\section{Resumo}

Ações de controle sanitário na área de alimentos devem ter constante aperfeiçoamento, para garantir a qualidade dos mesmos. As BPF (Boas Práticas de Fabricação) fazem parte de uma das ações de controle sanitário e esta, foi implantada em uma indústria de queijos, para uma melhora das condições higiênico-sanitárias e consequentemente da qualidade do produto. Foi escolhido um pequeno laticínio localizado na cidade de Piumhi-MG, para implantação do BPF. Foram realizadas coletas para análises de swabes, de equipamentos e das mãos dos funcionários, água e o queijo mais vendido, o provolone defumado sem tempero e posteriormente de dois exemplares de queijos frescos, tipo mussarela trança e tipo parmesão. Como resultado, na 
FERREIRA, F.S., MOURA, M.S. e SILVEIRA, A.C.P. Implantação de Boas Práticas de Fabricação (BPF) em um laticínio de Piumhi-MG. PUBVET, Londrina, V. 5, N. 13, Ed. 160, Art. 1082, 2011.

primeira análise os swabes se mostraram altamente contaminados, já numa segunda análise, após a implantação das BPF, houve uma redução na contaminação. Foi constatado que a maior dificuldade para a implantação das Boas Práticas de Fabricação é a condição higiênico-sanitária, principalmente no que diz respeito a higiene de funcionários e equipamentos.

Palavras-chave: controle da qualidade, higiene, queijo, saúde pública

\title{
Implementation of Good Manufacturing Practices (GMP) in a plant of Piumhi-Mg
}

\begin{abstract}
Sanitary control measures in the food must be constantly improved to ensure quality. GMP (Good Manufacturing Practices) are part of a sanitary control measures and this was implanted in an industry of cheese for an improvement of sanitary conditions and hence the product quality. We chose a small dairy located in the city of Piumhi-MG, to implement the GMP. Plants were sampled for analysis of swabs of equipment and the hands of officials, water and selling cheese, smoked provolone without seasoning and then two samples of fresh cheese, mozzarella and parmesan cheese braid. As a result, the first analysis the swab were highly contaminated, as a second analysis after the implementation of GMP, a reduction in contamination. It was found that the greatest difficulty in implementing the Good Manufacturing Practices is hygienic and sanitary condition, especially as regards the hygiene of staff and equipment.
\end{abstract}

Keywords: cheese, hygiene, public health, quality control

\section{Introdução}

Devido ao grande crescimento da população mundial, um grande desafio hoje é adequar a produção de alimentos, já que existem milhões de indivíduos famintos nos países subdesenvolvidos e ficam cada vez mais evidentes os 
FERREIRA, F.S., MOURA, M.S. e SILVEIRA, A.C.P. Implantação de Boas Práticas de Fabricação (BPF) em um laticínio de Piumhi-MG. PUBVET, Londrina, V. 5, N. 13, Ed. 160, Art. 1082, 2011.

problemas relativos à qualidade dos alimentos para consumo humano. A Organização Mundial da Saúde tem alertado para a necessidade de se coibir a contaminação de alimentos por agentes biológicos com potencial de causar danos à saúde (WORLD DECLARATION ON NUTRITION, 1992).

O Comitê WHO/FAO (1984) admite que doenças oriundas de alimentos contaminados seja provavelmente, o maior problema de saúde no mundo contemporâneo, principalmente em países da América Latina e do Caribe, onde as doenças veiculadas por alimentos são um dos principais fatores que contribuem para os índices de morbidade dos mesmos. Daí a importância de se discutir e estudar a qualidade higiênico-sanitária como fator de segurança alimentar.

Dos derivados do leite, o queijo se destaca como um grande problema na questão higiênico-sanitária, por ser um produto altamente manipulado, portanto, mais sujeito a contaminação. Em regiões com alta produção laticinista a preocupação com a qualidade dos alimentos produzidos é grande e crescente. Alguns programas para controle de contaminações e garantia da qualidade de produtos têm sido implantados em indústrias, dentre eles podemos citar as BPF (Boas Práticas de Fabricação). A mesma está regulamentada pela portaria no 326-SVS/MS de 30 de julho de 1997 do Ministério da Saúde.

A avaliação dessas BPF em estabelecimentos de produção ou de comercialização de alimentos, por meio de utilização de questionários apropriados, é citada como base para vistoria fiscal sanitária, como subsídio para qualificação e triagem de fornecedores, para a verificação, pelo próprio estabelecimento, do cumprimento das BPF, ou como base para a implantação do sistema Análise de Perigos e Pontos Críticos de Controle (APPCC) (QUEIROZ et al., 2000).

O presente trabalho teve como objetivo de implantar BPF (Boas Práticas de Fabricação) em uma indústria de queijos, para melhoria das condições higiênico-sanitárias e consequentemente da qualidade do produto. 
FERREIRA, F.S., MOURA, M.S. e SILVEIRA, A.C.P. Implantação de Boas Práticas de Fabricação (BPF) em um laticínio de Piumhi-MG. PUBVET, Londrina, V. 5, N. 13, Ed. 160, Art. 1082, 2011.

O pequeno laticínio escolhido para realização do trabalho tem aproximadamente 30 funcionários e está localizado na cidade de Piumhi-MG, uma cidade com aproximadamente 30.000 habitantes e que tem nos queijos uma importante fonte de renda. O laticínio produz variados tipos de queijos e comercializa os mesmos para todo o Brasil, uma vez que se localiza em uma área turística e "famosa" por seus queijos, a região da Serra da Canastra, sendo os mais vendidos o provolone, mussarela tipo trança e parmesão.

A indústria tem certificação pelo Serviço de Inspeção Municipal, mas deseja adquirir o selo do Serviço de Inspeção Federal, para expandir o seu comércio, já que atualmente seu produto é encontrado em todo Brasil, mas nas mãos dos populares "queijeiros", e também para melhorar a qualidade do produto oferecido. Para tal e para melhorar a qualidade de seus queijos, a indústria deverá implantar as normas de Boas Práticas de Fabricação conforme Portaria no 326 de 30 de julho de 1997 do Ministério da Saúde.

\section{Material e métodos}

Foi feito uma visita ao laticínio localizado na cidade de Piumhi-MG, na qual verificou-se os modo de produção dos queijos e maiores dificuldades em relação à questão higiênico-sanitária de acordo com a Portaria no 326 de 30 de julho de 1997 do Ministério da Saúde. Foi verificado que a indústria possui Serviço de Inspeção Municipal (S.I.M.).

Foram coletados dois swabes das mãos dos funcionários antes da higienização das mesmas na plataforma de recebimento do leite e dois swabes após a higienização das mesmas; um swabe dos garfos antes da higienização e um após; um swabe das mesas antes da higienização e um após; e um swabe das latas de fermento após a higienização feita no dia anterior. Os swabes foram armazenados em água peptonada para serem transportados para Uberlândia, devidamente refrigerados em caixa de isopor contendo gelo.

Nos swabes foram feitas análises para coliformes, utilizando ágar Eosina Azul de Metileno - EMB (nas diluições pura, $10^{-1}$ e $10^{-2}$ ), e bactérias mesófilas, 
FERREIRA, F.S., MOURA, M.S. e SILVEIRA, A.C.P. Implantação de Boas Práticas de Fabricação (BPF) em um laticínio de Piumhi-MG. PUBVET, Londrina, V. 5, N. 13, Ed. 160, Art. 1082, 2011.

utilizando ágar Padrão para contagem - PCA (nas diluições pura, $10^{-1}$ e $10^{-2}$ ), os mesmos foram incubados por 24 horas a temperatura de $37^{\circ} \mathrm{C}$.

Foi coletada uma amostra de água derivada do poço artesiano da Indústria. A amostra foi mantida resfriada em caixa de isopor com gelo em seu transporte até Uberlândia, MG.

Nas amostras de água também foi analisada a presença de coliformes e aeróbios mesófilos. Para análise de coliformes foi utilizado caldo lactosado, uma série com 5 (cinco) tubos; e para análise de mesófilos foi utilizado ágar Padrão para contagem - PCA (nas diluições pura e $10^{-1}$ ), conforme a Portaria $n$. 518, de 24 de março de 2004 (BRASIL, 2004).

O queijo mais vendido do laticínio em questão, provolone sem tempero, também foi analisado quanto a presença de Coliformes Totais, Staphylococcus coagulase positiva, Salmonella sp. e Listeria monocytogenes. A metodologia é padronizada pela Instrução Normativa 62 de 26/08/2003 do MAPA (BRASIL, 2003). Todas as análises foram feitas no Laboratório de Controle de qualidade e Segurança Alimentar da Universidade Federal de Uberlândia.

As análises para verificar a presença de coliformes totais foram feitas em caldo verde brilhante -3 séries de 3 tubos; nas diluições $10^{-2}, 10^{-3}$ e $10^{-4}$ incubados por 48 horas em temperatura de $37^{\circ} \mathrm{C}$.

Para Staphylococcus coagulase positiva, colocou-se $0,1 \mathrm{~mL}$ das seguints diluições $10^{-1}, 10^{-2}$ e $10^{-3}$ nas placas contendo ágar Baird-Parker e espalhou com alça Drigalski e incubou por 48 horas a $37^{\circ} \mathrm{C}$. Apresentando colônias características, colônias negras com ou sem presença de halo característico, foram repicadas em $0,1 \mathrm{~mL}$. de caldo $\mathrm{BHI}$ e incubado novamente por 24 horas a $37^{\circ} \mathrm{C}$ logo após adicionou-se plasma de coelho e foi incubado por mais 24 horas na mesma temperatura.

$\mathrm{Na}$ análise de Salmonella sp. diluiu-se $10 \mathrm{~g}$ de queijo em $90 \mathrm{ml}$. de água peptonada, esperou-se 24 horas incubado a $37^{\circ} \mathrm{C}$ para fazer o repique da bactéria em 0,1 mL. de caldo Rapaport e 1,0 mL. de caldo Selenito cistina, 
FERREIRA, F.S., MOURA, M.S. e SILVEIRA, A.C.P. Implantação de Boas Práticas de Fabricação (BPF) em um laticínio de Piumhi-MG. PUBVET, Londrina, V. 5, N. 13, Ed. 160, Art. 1082, 2011.

forma colocados em banho maria á $42^{\circ} \mathrm{C}$ por mais 24 horas e inoculados nos ágar Hectocu e XLD incubado por 24 horas a $37^{\circ} \mathrm{C}$.

$\mathrm{Na}$ análise de Listeria monocytogenes diluiu-se $10 \mathrm{~g}$ de queijo em $90 \mathrm{ml}$. de caldo universal ou caldo de enriquecimento para Listeria (UVM), incubado por 48 horas a $30-40^{\circ} \mathrm{C}$, depois ferveu em banho maria por 5 minutos e em seguida adicionou a fita LFS, em 10 minutos foi retirado a fita e realizado a leitura.

Foi realizada outra visita ao laticínio, na qual houve a apresentação dos resultados anteriores e um treinamento aos funcionários sobre a importância de uma correta higienização das mãos e dos equipamentos. Após a palestra os funcionários aprenderam na prática a maneira correta de lavar as mãos e sanitizar os equipamentos.

Logo após a palestra e uma demonstração prática foi então realizada a coleta de dois swabes das mãos recém-higienizadas, das mesas, das latas de fermento, dos tanques para mistura e dos garfos.

Para checagem da qualidade dos queijos frescos foram analisados dois tipos de queijos frescos (tipo parmesão e tipo mussarela trança) nos mesmos moldes da análise do queijo provolone coletado na primeira visita.

\section{Resultados e Discussão}

Os resultados foram separados para cada visita.

Assim como fizeram Figueiredo e Costa Neto (2001) ao implantarem HACCP (Análise de perigos e pontos críticos de controle) em uma indústria de biscoitos, foi realizada uma visita aos locais do processo de fabricação, desde o recebimento das matérias-primas até a expedição do produto acabado, com o objetivo de conhecer as etapas de produção além de verificar as condições das instalações.

Quanto à estrutura física da indústria foi possível constatar que sua localização é livre de focos de insalubridade, não há objetos em desuso e nem animais. O acesso a indústria é direto e independente, está livre de odores 
FERREIRA, F.S., MOURA, M.S. e SILVEIRA, A.C.P. Implantação de Boas Práticas de Fabricação (BPF) em um laticínio de Piumhi-MG. PUBVET, Londrina, V. 5, N. 13, Ed. 160, Art. 1082, 2011.

indesejáveis e não está exposta a inundações. Os pisos, bem como as paredes são lisos, resistentes, laváveis e de cores claras. As portas são devidamente identificadas e de vidro, as janelas também são de vidro e possuem uma tela de proteção contra a entrada de pragas, mas não se apresenta no mesmo nível da parede, o que pode facilitar o acúmulo de sujidades, mas como foi informado pelos funcionários a limpeza é feita diariamente. A disposição do teto impede o acúmulo de sujeira e se reduz ao mínimo a condensação e a formação de mofo. As lâmpadas são protegidas e a indústria é bem iluminada, além disso, as janelas são altas, o que impede de raios solares incidirem diretamente sobre os queijos. Há ventilação, porém a área se apresenta muito quente. Na área de manipulação dos queijos há um pedilúvio com água clorada, e não há citações sobre isto na legislação. O hall de entrada, e o ambiente para preparação de queijos se encontram de acordo com a Portaria n० 326 de 30 de julho de 1997 do Ministério da Saúde.

As instalações sanitárias e vestiários não apresentam comunicação com as áreas de produção, estando em bom estado de conservação e higiene, bem como a sala destinada ao Serviço de Inspeção Federal e o refeitório. O escoamento sanitário é ligado à rede de esgoto. Há uma placa de instruções afixada nos banheiros, nela consta a importância da lavagem das mãos após utilização do mesmo e algumas regras a serem a seguidas. Todos os banheiros têm papel-higiênico, detergente sem cheiro e papel-toalha não reciclado, os lixos têm acionamento por pedal e são cobertos por saco plástico em seu interior, conforme as exigências da Portaria no 326 de 30 de julho de 1997 do Ministério da Saúde.

Ao contrário do que foi encontrado por Gomes e Rodrigues (2006) ao implantar BPF em uma indústria de panificação de Natal - RN, segundo estes autores o banheiro utilizado pelos manipuladores não era de uso exclusivo destes, os manipuladores dividiam um único banheiro com todo o corpo de funcionários da panificadora. Desse modo o banheiro se encontrava 
FERREIRA, F.S., MOURA, M.S. e SILVEIRA, A.C.P. Implantação de Boas Práticas de Fabricação (BPF) em um laticínio de Piumhi-MG. PUBVET, Londrina, V. 5, N. 13, Ed. 160, Art. 1082, 2011.

constantemente em estado crítico de higiene exalando odores desagradáveis e era necessária a passagem pela produção para o uso do mesmo.

Quanto aos utensílios havia garfos de madeira e de aço inoxidável e os móveis (mesas, bancadas e prateleiras) são de aço inoxidável. Segundo a Portaria no 326 de 30 de julho de 1997 do Ministério da Saúde devem evitarse o uso de madeira e de outros materiais que não possam ser limpos e desinfetados adequadamente. Por isso foi solicitada a retirada dos equipamentos de madeira encontrados. Gomes e Rodrigues (2006) também encontram utensílios de madeira em uma indústria de panificação ao tentar implantar BPF e também sugeriram a troca dos mesmos.

Outra não conformidade encontrada foi à maneira como são guardados os garfos e leiras, que estavam com a parte que entra em contato com o produto, em contato com o ambiente. Foi sugerida uma mudança, guardar os garfos e leiras com a parte que entra em contato com o produto virado para baixo.

Nunca havia sido feita uma análise para verificar a qualidade da água utilizada dentro da indústria, a água utilizada na queijeira é proveniente de um poço artesiano localizado no interior da propriedade. A tabela 1 mostra os resultados da análise da água da indústria.

Tabela 1 - Resultado da análise da água coletada no dia 04/01/2010 em um laticínio, Piumhi-MG, Brasil.

\begin{tabular}{lll} 
Análise & Concentração & Resultado \\
\hline Coliformes & Pura & Ausência \\
Aeróbios Mesófilos & Pura & 39 UFC/MI \\
& $10^{-1}$ & 4 UFC/MI \\
\hline
\end{tabular}

Quanto ao abastecimento de água da indústria, a água utilizada foi considerada de boa qualidade já que segundo a Portaria n. 518, de 24 de março de 2004 a ausência de Coliformes Totais torna a água apta para o 
FERREIRA, F.S., MOURA, M.S. e SILVEIRA, A.C.P. Implantação de Boas Práticas de Fabricação (BPF) em um laticínio de Piumhi-MG. PUBVET, Londrina, V. 5, N. 13, Ed. 160, Art. 1082, 2011.

consumo e consequentemente para o seu uso na produção de alimentos e a contagem de bactérias mesófilas também se apresenta dentro do padrão. A eliminação de efluentes e águas residuais também está de acordo com a legislação.

Uma empresa terceirizada credenciada para desempenhar tal serviço na Vigilância Sanitária da cidade realiza o Controle de pragas da empresa, há iscas localizadas fora da área de produção, o que se apresenta correto em relação à Portaria no 326 de 30 de julho de 1997 do Ministério da Saúde. As pragas provocam danos ao homem, não só pelo risco à saúde que representam através de doenças transmitidas, mas também pelos estragos que causam, na estocagem dos alimentos, nas contaminações de embalagens, produtos e ambientes (GIORDANO, 2004).

Em um levantamento dos parâmetros que constam no manual das BPF em uma fábrica de iogurte situada no município do Rio de Janeiro $31,5 \%$ da empresa apresentava não conformidade e 2,8\% destas diziam respeito ao Controle integrado de pragas (SILVA, 2007). O mesmo não acontece na pequena indústria, onde o Controle Integrado de Pragas não apresenta inconformidades.

O depósito para produtos químicos localiza-se na área externa da empresa, e é devidamente identificado, cada produto lá dentro também possui uma identificação, bem como instruções para o uso em conformidade com a Portaria no 326 de 30 de julho de 1997 do Ministério da Saúde.

Quanto à higienização de funcionários, um funcionário contratado pela empresa já está começando a instalar as Boas Práticas de Fabricação, por isso já é possível ver dentro da empresa cartazes com as normas e instruções a serem seguidas para uma boa higienização.

Na entrada da área de produção há uma sala para higienização de botas e de mãos. O equipamento para higienização de botas tem acionamento por pedal, a pia para lavagem das mãos é de aço inoxidável e a torneira apresenta fechamento automático. Há uma saboneteira com detergente líquido e sem 
FERREIRA, F.S., MOURA, M.S. e SILVEIRA, A.C.P. Implantação de Boas Práticas de Fabricação (BPF) em um laticínio de Piumhi-MG. PUBVET, Londrina, V. 5, N. 13, Ed. 160, Art. 1082, 2011.

cheiro, o papel toalha utilizado é branco (não reciclado) e o lixo tem acionamento por pedal e é revestido por um saco plástico. Não é utilizado um sanitizante após o processo de lavagem das mãos e isso pode ter influenciado nos resultados encontrados nos swabes coletados das mãos dos funcionários antes e pós lavagem mostrados na tabela 2.

Tabela 2 - Resultado da análise das mãos dos funcionários antes e após a higienização.

\begin{tabular}{llll}
\hline Identificação & Situação & Análise & Resultado \\
Mão - funcionário 01 & Não lavada & Bactérias Mesófilas & Incontáveis \\
Mão - funcionário 01 & Não lavada & Coliformes Totais & Incontáveis \\
Mão - funcionário 01 & Lavada & Bactérias Mesófilas & Incontáveis \\
Mão - funcionário 01 & Lavada & Coliformes Totais & Incontáveis \\
Mão - funcionário 02 & Não lavada & Bactérias Mesófilas & Incontáveis \\
Mão - funcionário 02 & Não lavada & Coliformes Totais & Incontáveis \\
Mão - funcionário 02 & Lavada & Bactérias Mesófilas & Incontáveis \\
Mão - funcionário 02 & Lavada & Coliformes Totais & Incontáveis \\
\hline
\end{tabular}

O resultado igual, das mãos lavadas e não lavadas, confirma que a higienização não está sendo eficiente.

Em uma avaliação das Boas Práticas de Fabricação em indústrias de pão de queijo $59 \%$ das amostras das mãos dos funcionários foram observadas contagem de mesófilas superior a $10^{5} \mathrm{UFC} / \mathrm{mão}$, além da presença de coliformes totais em $93,1 \%$ das amostras e de coliformes fecais em 34,5\%. Estes resultados indicam hábitos anti-higiênicos por parte dos manipuladores de alimentos, bem como processo de higienização das mãos inadequado, uma vez que $70 \%$ das amostras foram coletadas após a higienização das mesmas (TOMICH et al., 2005).

O mesmo aconteceu no laticínio os resultados da tabela 2 indicam hábitos não higiênicos dos funcionários além de uma higienização deficiente, 
FERREIRA, F.S., MOURA, M.S. e SILVEIRA, A.C.P. Implantação de Boas Práticas de Fabricação (BPF) em um laticínio de Piumhi-MG. PUBVET, Londrina, V. 5, N. 13, Ed. 160, Art. 1082, 2011.

pelo fato de os swabes terem sido coletados antes de depois da lavagem das mãos. Essa higienização deficiente pode interferir na qualidade do produto final.

Gomes e Rodrigues (2006) ao implantar BPF em uma indústria de panificação de Natal - RN verificaram que durante o processo não era observado à assepsia das mãos dos manipuladores ao iniciar o processo, nem a assepsia após manipular matéria prima e partir para produtos prontos, facilitando assim a contaminação cruzada.

O mesmo também pode ser observado no laticínio analisado quando alguns funcionários não lavavam as mãos ao entrar na área da produção, havendo então a necessidade de se realizar um treinamento para ressaltar a importância da lavagem das mãos.

Os funcionários do laticínio têm á sua disposição Equipamentos de Proteção Individual (EPIs) necessários (botas de borracha, touca, protetor auditivo, jaleco branco e avental de plástico) e usam os mesmos corretamente.

Quanto a higienização dos equipamentos, a mesma é realizada após o término da produção, o produto utilizado é a água oxigenada, e o enxágüe é feito com água em abundância e nenhum equipamento é esfregado. A limpeza é realizada com detergente, sempre que necessário, durante a produção. Os resultados dos swabes dos equipamentos, já higienizados ou não, se encontram na tabela 3.

De acordo com a Tabela 3 é possível notar que a higienização dos equipamentos não se apresenta eficiente, sendo necessárias modificações tanto nos produtos utilizados como na forma de realizar a limpeza. Assim como encontrado por Elias e Madrona (2008), ao avaliar uma indústria de embutidos cárneos, os equipamentos apresentaram sujidade visível após higienização.

No laticínio o queijo mais comercializado tem sido o queijo tipo provolone defumado, não temperado. Por isso foi escolhido para análise nessa primeira visita, os resultados estão demonstrados na tabela 4. 
FERREIRA, F.S., MOURA, M.S. e SILVEIRA, A.C.P. Implantação de Boas Práticas de Fabricação (BPF) em um laticínio de Piumhi-MG. PUBVET, Londrina, V. 5, N. 13, Ed. 160, Art. 1082, 2011.

Tabela 3 - Resultados das análises dos swabes dos equipamentos de um laticínio, Piumhi-MG.

\begin{tabular}{|c|c|c|c|c|}
\hline Equipamento & Situação & Análise & Diluição & Resultado \\
\hline Garfos & Antes da higienização & Bactérias Mesófilas & $\begin{array}{l}\text { Pura } \\
10^{-1} \\
10^{-2}\end{array}$ & $\begin{array}{l}\text { Incontáveis } \\
\text { Incontáveis } \\
\text { Incontáveis }\end{array}$ \\
\hline Garfos & Antes da higienização & Coliformes Totais & $\begin{array}{l}\text { Pura } \\
10^{-1} \\
10^{-2}\end{array}$ & $\begin{array}{l}\text { Incontáveis } \\
\text { Incontáveis } \\
\text { Incontáveis }\end{array}$ \\
\hline Garfos & Após a higienização & Bactérias Mesófilas & $\begin{array}{l}\text { Pura } \\
10^{-1} \\
10^{-2}\end{array}$ & $\begin{array}{l}\text { Incontáveis } \\
\text { Incontáveis } \\
\text { Incontáveis }\end{array}$ \\
\hline Garfos & Após a higienização & Coliformes Totais & $\begin{array}{l}\text { Pura } \\
10^{-1} \\
10^{-2}\end{array}$ & $\begin{array}{l}\text { Incontáveis } \\
\text { Incontáveis } \\
\text { Incontáveis }\end{array}$ \\
\hline Mesas & Antes da higienização & Bactérias Mesófilas & $\begin{array}{l}\text { Pura } \\
10^{-1} \\
10^{-2}\end{array}$ & $\begin{array}{l}\text { Incontáveis } \\
\text { Incontáveis } \\
\text { Incontáveis }\end{array}$ \\
\hline Mesas & Antes da higienização & Coliformes Totais & $\begin{array}{l}\text { Pura } \\
10^{-1} \\
10^{-2}\end{array}$ & $\begin{array}{l}\text { Incontáveis } \\
\text { Incontáveis } \\
\text { Incontáveis }\end{array}$ \\
\hline Mesas & Após a higienização & Bactérias Mesófilas & $\begin{array}{l}\text { Pura } \\
10^{-1} \\
10^{-2}\end{array}$ & $\begin{array}{l}\text { Incontáveis } \\
7 \mathrm{UFC/mL} \\
5 \mathrm{UFC} / \mathrm{mL}\end{array}$ \\
\hline Mesas & Após a higienização & Coliformes Totais & $\begin{array}{l}\text { Pura } \\
10^{-1} \\
10^{-2}\end{array}$ & $\begin{array}{l}\text { Incontáveis } \\
\text { Incontáveis } \\
\text { Incontáveis }\end{array}$ \\
\hline $\begin{array}{l}\text { Latas de } \\
\text { fermento }\end{array}$ & $\begin{array}{l}\text { Higienizadas no dia } \\
\text { anterior }\end{array}$ & Bactérias Mesófilas & $\begin{array}{l}\text { Pura } \\
10^{-1} \\
10^{-2}\end{array}$ & $\begin{array}{l}\text { Incontáveis } \\
8 \mathrm{UFC} / \mathrm{mL} \\
7 \mathrm{UFC} / \mathrm{mL}\end{array}$ \\
\hline $\begin{array}{l}\text { Latas de } \\
\text { fermento }\end{array}$ & $\begin{array}{l}\text { Higeinizadas no dia } \\
\text { anterior }\end{array}$ & Coliformes Totais & $\begin{array}{l}\text { Pura } \\
10^{-1} \\
10^{-2}\end{array}$ & $\begin{array}{l}\text { Incontáveis } \\
\text { Incontáveis } \\
\text { Incontáveis }\end{array}$ \\
\hline
\end{tabular}


FERREIRA, F.S., MOURA, M.S. e SILVEIRA, A.C.P. Implantação de Boas Práticas de Fabricação (BPF) em um laticínio de Piumhi-MG. PUBVET, Londrina, V. 5, N. 13, Ed. 160, Art. 1082, 2011.

Tabela 4 - Análise do Queijo tipo Provolone defumado não temperado de um laticínio, Piumhi-MG, Brasil.

\begin{tabular}{l|l}
\hline Análise & Resultado \\
\hline Coliformes Totais & Ausentes \\
Staphylococcus aureus & Ausentes \\
Salmonella sp. & Ausentes \\
Listeria sp. & Ausentes \\
\hline
\end{tabular}

No queijo provolone defumado não temperado analisado provavelmente não foi detectada a presença de contaminantes, provavelmente pelo processo de defumação que pode ter eliminado bactérias contaminantes, ou até mesmo o fato de o mesmo possuir menor umidade, o que impede a sobrevivência e multiplicação de microorganismos.

O leite (matéria-prima) é recebido na empresa na parte da manhã, até as 11 horas, em latões. Neste momento são realizadas análises de acidez, crioscopia, densidade e porcentagem de gordura. Há um pequeno laboratório para estas análises localizado na plataforma de recebimento do leite. Mesmo sendo recebida em latões, e não em um caminhão tanque isotérmico, a matéria prima chegava em boas condições na industria como constatado na primeira visita.

No laticínio analisado os problemas referentes à manutenção do pasteurizador são frequentes. Porém não há dados que comprove uma pasteurização eficiente por parte da indústria, o que ainda se faz necessário.

É importante ressaltar, que além de uma pasteurização inadequada do leite a contaminação pós-pasteurização, a utilização de fermentos inativos e temperaturas inadequadas, e incorretas condições de manufatura e armazenagem também podem contribuir de forma efetiva para a má qualidade do queijo (MANDIL, 1982). 
FERREIRA, F.S., MOURA, M.S. e SILVEIRA, A.C.P. Implantação de Boas Práticas de Fabricação (BPF) em um laticínio de Piumhi-MG. PUBVET, Londrina, V. 5, N. 13, Ed. 160, Art. 1082, 2011.

Foi constatado na primeira visita que o responsável técnico pela queijeira apresentava conhecimento suficiente sobre as boas práticas de produção, e ainda não havia conseguido implantá-las pela dificuldade de analisar os produtos e convencer os funcionários do laticínio sobre a importância de tal ferramenta, tornando viável a implantação das BPF (Boas Práticas de Fabricação) até uma segunda visita.

Após a apresentação dos resultados da primeira visita aos responsáveis, todos os materiais de madeira foram retirados da empresa, permanecendo somente os de aço inoxidável, a maneira de guardar os garfos também foi modificada, a parte que entra em contato com o produto foi virada para baixo.

Os funcionários da empresa também passaram por um treinamento sobre higiene baseado na Portaria no 326 de 30 de julho de 1997 do Ministério da Saúde, em que aprenderam na prática a maneira correta de lavar as mãos e higienizar os equipamentos e a indústria, o que se refletiu no resultado das análises dos swabes das mãos e dos equipamentos da queijeira como demonstrado nas tabelas 5 e 6 respectivamente.

Tabela 5 - Resultado da análise das mãos dos funcionários após a higienização e sanitização na $2^{\mathrm{a}}$ visita ao laticínio, Piumhi - MG.

\begin{tabular}{l|lll}
\hline Identificação & Análise & Diluição & Resultado \\
\hline Mão - Funcionário 01 & Bactérias & Pura & $10 \mathrm{UFC} / \mathrm{mL}$ \\
& Mesófilas & $10^{-1}$ & $7 \mathrm{UFC} / \mathrm{mL}$ \\
& & $10^{-2}$ & Ausentes \\
Mão - Funcionário 01 & Coliformes & Pura & $1 \mathrm{UFC} / \mathrm{mL}$ \\
& Totais & $10^{-1}$ & $1 \mathrm{UFC} / \mathrm{mL}$ \\
& & $10^{-2}$ & Ausentes \\
Mão - Funcionário 02 & Bactérias & Pura & $7 \mathrm{UFC} / \mathrm{mL}$ \\
& Mesófilas & $10^{-1}$ & $1 \mathrm{UFC} / \mathrm{mL}$ \\
Mão - Funcionário 02 & Coliformes & $10^{-2}$ & $1 \mathrm{UFC} / \mathrm{MI}$ \\
& Totais & $10^{-1}$ & Ausentes \\
& & $10^{-2}$ & Ausentes \\
& & & Ausentes \\
\hline
\end{tabular}


FERREIRA, F.S., MOURA, M.S. e SILVEIRA, A.C.P. Implantação de Boas Práticas de Fabricação (BPF) em um laticínio de Piumhi-MG. PUBVET, Londrina, V. 5, N. 13, Ed. 160, Art. 1082, 2011.

Tabela 6 - Resultado da análise dos equipamentos após a higienização na $2^{\mathrm{a}}$ visita ao laticínio, Piumhi-MG.

\begin{tabular}{|c|c|c|c|}
\hline Identificação & Análise & Diluição & Resultado \\
\hline \multirow[t]{3}{*}{ Mesas } & Coliformes Totais & Pura & Ausentes \\
\hline & & $10^{-1}$ & Ausentes \\
\hline & & $10^{-2}$ & Ausentes \\
\hline \multirow[t]{3}{*}{ Mesas } & Bactérias Mesófilas & Pura & $10 \mathrm{UFC} / \mathrm{mL}$ \\
\hline & & $10^{-1}$ & $10 \mathrm{UFC} / \mathrm{mL}$ \\
\hline & & $10^{-2}$ & $9 \mathrm{UFC} / \mathrm{mL}$ \\
\hline \multirow[t]{3}{*}{ Latas de fermento } & Coliformes Totais & Pura & Ausentes \\
\hline & & $10^{-1}$ & Ausentes \\
\hline & & $10^{-2}$ & $1 \mathrm{UFC} / \mathrm{mL}$ \\
\hline \multirow[t]{3}{*}{ Latas de fermento } & Bactérias Mesófilas & Pura & Incontáveis \\
\hline & & $10^{-1}$ & Incontáveis \\
\hline & & $10^{-2}$ & $8 \mathrm{UFC} / \mathrm{mL}$ \\
\hline Tanques & Coliformes Totais & Pura & Ausentes \\
\hline \multirow[t]{2}{*}{ mistura } & & $10^{-1}$ & $10 \mathrm{UFC} / \mathrm{mL}$ \\
\hline & & $10^{-2}$ & $9 \mathrm{UFC} / \mathrm{mL}$ \\
\hline Tanques & Bactérias Mesófilas & Pura & Incontáveis \\
\hline \multirow[t]{2}{*}{ mistura } & & $10^{-1}$ & $10 \mathrm{UFC} / \mathrm{mL}$ \\
\hline & & $10^{-2}$ & $8 \mathrm{UFC} / \mathrm{mL}$ \\
\hline \multirow[t]{3}{*}{ Garfos } & Coliformes Totais & Pura & Ausentes \\
\hline & & $10^{-1}$ & Ausentes \\
\hline & & $10^{-2}$ & Ausentes \\
\hline \multirow[t]{3}{*}{ Garfos } & Bactérias Mesófilas & Pura & $7 \mathrm{UFC} / \mathrm{mL}$ \\
\hline & & $10^{-1}$ & $1 \mathrm{UFC} / \mathrm{mL}$ \\
\hline & & $10^{-2}$ & $1 \mathrm{UFC} / \mathrm{mL}$ \\
\hline
\end{tabular}

Para a lavagem das mãos foi utilizado um detergente neutro, sem cheiro, o mesmo que já era utilizado na empresa, e logo após, um sanitizante, no caso álcool em gel a $62 \%$, o que pode ter contribuido para a redução na contagem de bactérias mesófilas e de coliformes totais. Segundo Kochanski et al. (2009) os microrganismos aeróbios mesófilos podem ser removidos pelos processos 
FERREIRA, F.S., MOURA, M.S. e SILVEIRA, A.C.P. Implantação de Boas Práticas de Fabricação (BPF) em um laticínio de Piumhi-MG. PUBVET, Londrina, V. 5, N. 13, Ed. 160, Art. 1082, 2011.

convencionais de limpeza, envolvendo detergente, água corrente e sanitização com álcool a 70\%.

A Tabela 7 apresenta um comparativo entre as análises dos swabes das mãos dos funcionários antes e depois do treinamento sobre a maneira correta de lavá-las.

Tabela 7 - Comparativo entre os swabes das mãos dos funcionários lavadas antes e depois da palestra a respeito da implantação das Boas Praticas de Fabricação em um laticínio de Piumhi-MG, Brasil.

\begin{tabular}{|c|c|c|c|c|}
\hline & Análise & Diluição & Antes & Depois \\
\hline Mão & Coliformes & Pura & Incontáveis & $1 \mathrm{UFC} / \mathrm{mL}$ \\
\hline Funcionário & Totais & $10^{-1}$ & Incontáveis & $1 \mathrm{UFC} / \mathrm{mL}$ \\
\hline 01 & & $10^{-2}$ & Incontáveis & Ausentes \\
\hline Mão & Bactérias & Pura & Incontáveis & $10 \mathrm{UFC} / \mathrm{mL}$ \\
\hline Funcionário & Mesófilas & $10^{-1}$ & Incontáveis & $7 \mathrm{UFC} / \mathrm{mL}$ \\
\hline 01 & & $10^{-2}$ & Incontáveis & Ausentes \\
\hline Mão & Coliformes & Pura & Incontáveis & Ausentes \\
\hline Funcionário & Totais & $10^{-1}$ & Incontáveis & Ausentes \\
\hline 02 & & $10^{-2}$ & Incontáveis & Ausentes \\
\hline Mão & Bactérias & Pura & Incontáveis & $7 \mathrm{UFC} / \mathrm{mL}$ \\
\hline Funcionário & Mesófilas & $10^{-1}$ & Incontáveis & $1 \mathrm{UFC} / \mathrm{mL}$ \\
\hline 02 & & $10^{-2}$ & Incontáveis & $1 \mathrm{UFC} / \mathrm{mL}$ \\
\hline
\end{tabular}

Os resultados comprovam que além de uma boa limpeza também é necessária uma boa sanitização. Soares et al. (2006) explicam que limpeza e sanitização são processos diferentes. Limpeza é a remoção de resíduos de alimentos e sujidades de uma superfície, já a sanitização é o processo de redução do número de microrganismos na superfície a níveis seguros.

Almeida et al. (1995) usando a mesma metodologia para análise também encontraram uma diminuição no número de bactérias mesófilas presentes na 
FERREIRA, F.S., MOURA, M.S. e SILVEIRA, A.C.P. Implantação de Boas Práticas de Fabricação (BPF) em um laticínio de Piumhi-MG. PUBVET, Londrina, V. 5, N. 13, Ed. 160, Art. 1082, 2011.

mão de manipuladores de alimentos após um treinamento sobre higiene ministrado.

A higienização dos equipamentos deve ser periódica e acontecer antes e depois da produção. Na implantação de BPF em uma indústria de panificação de Natal - RN não existia nenhum procedimento periódico de higienização dos equipamentos, observava-se uma limpeza esporádica a cargo dos manipuladores (GOMES; RODRIGUES, 2006). Já na queijeira onde foram implantadas as Boas Práticas de Fabricação havia um procedimento periódico de limpeza, mas o mesmo não se apresentava eficiente.

No laticínio em questão para a higienização de equipamentos a água oxigenada foi trocada pela água clorada. O cloro, em suas várias formas, especialmente na de sais de hipoclorito, é um dos sanitizantes empregados com mais sucesso nas indústrias de alimentos (KIM et al., 1999).

É possível notar uma redução de contaminação tanto por bactérias mesófilas quanto por coliformes, possivelmente pela troca do uso da água oxigenada pela água clorada na higienização de equipamentos e pelo fato de passar a realizar a higienização não só após a produção, mas também antes do inicio da mesma no dia seguinte, além de esfregar os equipamentos, conforme a tabela 8 .

Assim como Tomich et al. (2005), que avaliaram as boas práticas de fabricação em uma indústria de pães de queijo, o maior problema encontrado na avaliação e implantação das Boas Práticas de fabricação é a higiene tanto de equipamentos, quanto dos funcionários.

Como nunca havia sido feita a análise de queijos frescos produzidos na indústria foram escolhidas duas variedades de queijos frescos e coletadas 1 amostra de cada após a segunda visita, sua análise se encontra na tabela 9. 
FERREIRA, F.S., MOURA, M.S. e SILVEIRA, A.C.P. Implantação de Boas Práticas de Fabricação (BPF) em um laticínio de Piumhi-MG. PUBVET, Londrina, V. 5, N. 13, Ed. 160, Art. 1082, 2011.

Tabela 8 - Comparativo entre os swabes dos equipamentos lavados antes e depois da palestra a respeito da implantação das Boas Praticas de Fabricação em um laticínio de Piumhi-MG, Brasil.

\begin{tabular}{|c|c|c|c|c|}
\hline Equipamento & Análise & Diluição & Antes & Depois \\
\hline Mesas & $\begin{array}{l}\text { Bactérias } \\
\text { Mesófilas }\end{array}$ & $\begin{array}{l}\text { Pura } \\
10^{-1} \\
10^{-2}\end{array}$ & $\begin{array}{l}\text { Incontáveis } \\
7 \mathrm{UFC/ml} \\
5 \mathrm{UFC} / \mathrm{ml}\end{array}$ & $\begin{array}{l}10 \mathrm{UFC} / \mathrm{mL} \\
10 \mathrm{UFC} / \mathrm{mL} \\
9 \mathrm{UFC} / \mathrm{mL}\end{array}$ \\
\hline Mesas & $\begin{array}{l}\text { Coliformes } \\
\text { Totais }\end{array}$ & $\begin{array}{l}\text { Pura } \\
10^{-1} \\
10^{-2}\end{array}$ & $\begin{array}{l}\text { Incontáveis } \\
\text { Incontáveis } \\
\text { Incontáveis }\end{array}$ & $\begin{array}{l}\text { Ausentes } \\
\text { Ausentes } \\
\text { Ausentes }\end{array}$ \\
\hline $\begin{array}{l}\text { Latas de } \\
\text { fermento }\end{array}$ & $\begin{array}{l}\text { Bactérias } \\
\text { Mesófilas }\end{array}$ & $\begin{array}{l}\text { Pura } \\
10^{-1} \\
10^{-2}\end{array}$ & $\begin{array}{l}\text { Incontáveis } \\
8 \mathrm{UFC} / \mathrm{ml} \\
7 \mathrm{UFC} / \mathrm{ml}\end{array}$ & $\begin{array}{l}\text { Incontáveis } \\
\text { Incontáveis } \\
8 \mathrm{UFC} / \mathrm{mL}\end{array}$ \\
\hline $\begin{array}{l}\text { Latas de } \\
\text { fermento }\end{array}$ & $\begin{array}{l}\text { Coliformes } \\
\text { Totais }\end{array}$ & $\begin{array}{l}\text { Pura } \\
10^{-1} \\
10^{-2}\end{array}$ & $\begin{array}{l}\text { Incontáveis } \\
\text { Incontáveis } \\
\text { Incontáveis }\end{array}$ & $\begin{array}{l}\text { Ausentes } \\
\text { Ausentes } \\
1 \mathrm{UFC} / \mathrm{mL}\end{array}$ \\
\hline Garfos & $\begin{array}{l}\text { Bactérias } \\
\text { Mesófilas }\end{array}$ & $\begin{array}{l}\text { Pura } \\
10^{-1} \\
10^{-2}\end{array}$ & $\begin{array}{l}\text { Incontáveis } \\
\text { Incontáveis } \\
\text { Incontáveis }\end{array}$ & $\begin{array}{l}7 \mathrm{UFC} / \mathrm{mL} \\
1 \mathrm{UFC} / \mathrm{mL} \\
1 \mathrm{UFC} / \mathrm{mL}\end{array}$ \\
\hline
\end{tabular}


FERREIRA, F.S., MOURA, M.S. e SILVEIRA, A.C.P. Implantação de Boas Práticas de Fabricação (BPF) em um laticínio de Piumhi-MG. PUBVET, Londrina, V. 5, N. 13, Ed. 160, Art. 1082, 2011.

Tabela 9 - Análise dos queijos tipo parmesão e tipo mussarela trança de um laticínio, Piumhi-MG, Brasil.

\begin{tabular}{l|lll}
\hline Queijo & Análise & Diluição & Resultado \\
\hline Tipo Parmesão & Coliformes Totais & $10^{-2}$ & Ausente \\
& & $10^{-3}$ & Ausente \\
Tipo Parmesão & & $10^{-4}$ & Ausente \\
& Staphylococcus & - & $42 \times 10^{3} \mathrm{UFC} / \mathrm{g}$ \\
Tipo Parmesão & coagulase positiva & & \\
Tipo Parmesão & Salmonella sp. & - & Ausente \\
& Listeria & - & Ausente \\
Tipo Mussarela & monocytogenes & & \\
Trança & Coliformes Totais & $10^{-2}$ & Ausente \\
Tipo Mussarela & Staphylococcus & - & Ausente \\
Trança & coagulase positiva & & Ausente \\
Tipo Mussarela & Salmonella sp. & - & $2,98 \quad \mathrm{x} \quad 10^{3}$ \\
Trança & & & UFC/g \\
Tipo Mussarela & Listeria & Ausente \\
Trança & monocytogenes & & Ausente \\
\hline
\end{tabular}

É importante ressaltar que o queijo parmesão analisado é fresco, fabricado no dia da coleta, ainda não maturado, e armazenado resfriado para que não ocorra a maturação.

O tempo de maturação do queijo parmesão deve ser de, no mínimo, seis meses, podendo ultrapassar os dois anos. Deve ser armazenado em temperatura não superior a $18^{\circ} \mathrm{C}$ (PERRY, 2004).

O queijo fresco produzido na queijeira Van-Ita não apresentou após a segunda visita contaminação para Coliformes Totais, ao contrário de outros queijos produzidos na região de Piumhi-MG que apresentaram em 28 amostras, 8 contaminadas (PEREIRA et al., 2008). A não contaminação por Coliformes já se apresentou como uma melhora após a implantação das BPF. 
FERREIRA, F.S., MOURA, M.S. e SILVEIRA, A.C.P. Implantação de Boas Práticas de Fabricação (BPF) em um laticínio de Piumhi-MG. PUBVET, Londrina, V. 5, N. 13, Ed. 160, Art. 1082, 2011.

Porém os queijos frescos apresentaram contaminação por Staphylococcus coagulase positiva, porque segundo a Resolução RDC no 12, de 2 de janeiro de 2001, a contagem mínima deveria ser $10^{3}$ UFC/g (BRASIL, 2001).

Segundo Queiroz et al. (2000), essa bactéria na grande maioria das vezes é proveniente de lesões sépticas das mãos de funcionários e para Franco e Landgraf (2002), a presença de números elevados de Staphylococcus coagulase positiva é uma indicação de perigo potencial à saúde pública devido à enterotoxina estafilocócica presente no alimento, bem como à sanificação questionável, principalmente quando o processo envolve manipulação do alimento, como os queijos, por ser um microrganismo que vive nas mucosas e na pele.

Quintana e Carneiro (2007) analisando queijos tipo mussarela da cidade de Morrinhos-GO não encontraram Staphylococcus coagulase positiva acima de $1,0 \times 10^{1} \mathrm{UFC} / \mathrm{g}$, mostrando uma melhor qualidade dos mesmos naquela cidade em comparação com os provenientes da queijeira Van-Ita de PiumhiMG.

Segundo a Resolução RDC no 12, de 2 de janeiro de 2001 Salmonella sp. e Listeria monocytogenes devem estar ausentes nos queijos, o que foi confirmado pela análise.

\section{Conclusão}

As Boas Práticas de Fabricação foram implantadas na indústria de queijos escolhida, e estão contribuindo para a melhora das condições higiênicosanitárias e consequentemente da qualidade do produto, sendo a falta de higiene dos funcionários, a maior dificuldade encontrada durante o processo de implantação.

Desta forma, este trabalho deverá ser contínuo, sendo necessárias mais análises e um acompanhamento por parte dos gestores da empresa. Deve-se obedecer a uma mudança concreta de postura de todos os envolvidos para que 
FERREIRA, F.S., MOURA, M.S. e SILVEIRA, A.C.P. Implantação de Boas Práticas de Fabricação (BPF) em um laticínio de Piumhi-MG. PUBVET, Londrina, V. 5, N. 13, Ed. 160, Art. 1082, 2011.

as Boas Práticas de Fabricação sejam efetivamente implantadas com sucesso e gerem melhores resultados no produto final.

\section{Referências}

ALMEIDA, R. C. C., KUAYE, A. Y., SERRANO, A. M., ALMEIDA, P. F. Avaliação e controle da qualidade microbiológica de mãos de manipuladores de alimentos. Revista Saúde Pública, no 29, 290-294p., 1995.

BRASIL. Ministério da Saúde, Secretaria de Vigilância Sanitária. Portaria no 326-SVS/MS de 30 de julho de 1997. Aprova o regulamento técnico; condições higiênicos-sanitárias e de boas práticas de fabricação para estabelecimentos produtores/industrializadores e de alimentos. Disponível em: <http://www.anvisa.gov.br/legis/portarias/326_97.htm>, acesso em 15 de maio de 2010.

BRASIL. Ministério da Saúde, Secretaria de Vigilância Sanitária Resolução RDC no 12, de 2 de janeiro de 2001. Regulamento técnico sobre padrões microbiológicos para alimentos. Disponível em: http://www.anvisa.gov.br/legis/resol/12_01rdc.htm, acesso em: 05 de junho de 2010.

BRASIL. Ministério da Agricultura, Pecuária e Abastecimento. Instrução Normativa no 62, de 26 de agosto de 2003. Oficializa os Métodos Analíticos Oficiais para Análises Microbiológicas para Controle de Produtos de Origem Animal e Água. Disponível em: $<$ http://extranet.agricultura.gov.br/sislegis-

consulta/consultarLegislacao.do?operacao $=$ visualizar\&id $=2851>$, acesso em 18 de maio de 2010.

BRASIL. Ministério da Saúde. Agência Nacional de Vigilância Sanitária.Portaria n. 518, de 25 de março de 2004. Estabelece os procedimentos e responsabilidades relativos ao controle e vigilância da qualidade da água para consumo humano e seu padrão de potabilidade, e dá outras providências. Disponível em: < http://www.agrolab.com.br/portaria\%20518_04.pdf >, acesso em 29 de junho de 2010.

ELIAS, A. H., MADRONA, G. S. Avaliação de uma indústria produtora de embutidos cárneos quanto à higiene e legislação vigente no Brasil. Revista Brasileira de Tecnologia Agroindustrial. v. 02, n. 02, 71-81p., 2008.

FIGUEIREDO, V. F., COSTA NETO, P. L. O. Implantação do HACCP na Indústria de Alimentos. Gestão \& Produção. v.8, n.1, p.100-111, 2001.

FRANCO, B. D. G. de M.; LANDGRAF, M. Microbiologia dos Alimentos. São Paulo: Editora Atheneu, 2002.

GIORDANO, J. C. Controle integrado de pragas - C.I.P., 2004. Disponível em: < http://www.flavorfood.com.br/cip.pdf>, acesso em 09 de junho de 2010.

GOMES, H. V., RODRIGUES, R. K. Boas Práticas de Fabricação na Indústria de Panificação. In: XXVI ENEGEP, 2006, Fortaleza. Anais.... Disponível em: <http://www.abepro.org.br/biblioteca/ENEGEP2006_TR470321_7479.pdf> , acesso em 02 de junho de 2010. 
FERREIRA, F.S., MOURA, M.S. e SILVEIRA, A.C.P. Implantação de Boas Práticas de Fabricação (BPF) em um laticínio de Piumhi-MG. PUBVET, Londrina, V. 5, N. 13, Ed. 160, Art. 1082, 2011.

KIM, J. G.; YOUSEF, E., DAVE, S. Application of ozone for enhancing the microbiological safety and quality of foods: a review. Journal of Food Protection, v. 62, n. 9, 1071-1087 p., 1999.

KOCHANSKI, S., PIEROZAN, M. K., MOSSI, A. J., TREICHEL, H., CANSIAN, R. L., GHISLENI, C. P., TONIAZZO, G. Avaliação das condições microbiológicas de uma unidade de alimentação e nutrição. Alimentos e Nutrição Araraquara. v.20, n. 4, 2009.

MANDIL, A., MORAIS, V. A. D., PEREIRA, M. L. Staphylococcus aureus em queijos "tipo Minas". Ciência e Tecnologia de Alimentos, v.2, 233-241 p., 1982.

PEREIRA, K. C.; DE SÁ, O. R.; PEREIRA, C. K. Avaliação da qualidade higiênico-sanitária do queijo canastra e de sua matéria-prima produzidos na região de São Roque de Minas (MG). Ciência et Praxis v. 1, n. 2, 2008.

PERRY, K. S. P. Queijos: Aspectos químicos, bioquímicos e microbiológicos, Química Nova, v. 27, n. 2, p. 293-300, 2004.

QUEIROZ, A.T.A., RODRIGUES, C.R., ALVEZ, G.G., KAKISAKA, L.T. Boas práticas de fabricação em restaurantes self- service a quilo. Higiene alimentar, v.14, n. 78/79, p.45-49, 2000.

QUINTANA, R. C., CARNEIRO, L. C. Avaliação das condições higiênico-sanitárias dos queijos minas frescal e mussarela produzidos na cidade de Morrinhos - GO. Revista Brasileira de Saúde e Produção Animal, v.8, n.3, 205-211 p., 2007.

SILVA, W. O. Levantamento dos parâmetros referentes ao manual das boas práticas de fabricação em uma fábrica de iogurte situada no Rio de Janeiro. Pubvet, v. 1, n. 9, Ed. 9 Art. 59, 2007. Disponível em: < http://www.pubvet.com.br/artigos_det.asp?artigo=59>, acesso em 02 de junho de 2010.

SOARES, A. G., OliVeirA, A. G. M., FONSECA, M. J. O., FREIRE JÚNIOR, M. Boas Práticas de Manipulação em Bancos de Alimentos. Rio de Janeiro: Embrapa Agroindústria de Alimentos, 2006.

TOMICH, R.G. P., TOMICH, T. R., AMARAL C. A. A., JUNQUEIRA, R. G., PEREIRA, A. J. G. Avaliação das boas práticas de fabricação em indústrias de pão de queijo. Ciência e Tecnolologia em Alimentos, Campinas, 115-120 p., 2005

World Declaration on Nutrition. In: FAO/WHO International Conference on Nutrition; 1992; Roma, Itália. Disponível em:

<http://www.fao.org/waicent/faoinfo/economic/esn/icn/icnconts.htm>, acesso em 15 de maio de 2010.

World Health Organization. The role of food safety in health and development. Genebra; 1984. 